\title{
Prevalence of self-reported early glaucoma eye drop bottle exhaustion and associated risk factors: a patient survey
}

Daniel B Moore ${ }^{1}$, Charlene Walton ${ }^{2}$, Kristy L Moeller ${ }^{1}$, Mark A Slabaugh ${ }^{1}$, Raghu C Mudumbai ${ }^{1}$ and Philip P Chen ${ }^{\text {* }}$

\begin{abstract}
Background: One barrier to patient adherence with chronic topical glaucoma treatment is an inadequate amount of medication available between prescription refills. We examined the self-reported prevalence of early exhaustion of glaucoma eye drops prior to a scheduled refill, and associated risk factors.

Methods: This cross-sectional survey was performed at a University-based clinical practice. Glaucoma patients at the University of Washington who were experienced with eye drop application and were on a steady regimen of self-administered glaucoma drops in both eyes took a survey at the time of clinic examination. The main outcome measure was self-reported early eye drop bottle exhaustion.

Results: 236 patients were eligible and chose to participate. In general, patients included were relatively healthy (mean 2.3 comorbid medical conditions). Sixty patients (25.4\%) reported any problem with early exhaustion of eye drop bottles, and this was associated with visual acuity $\leq 20 / 70$ in the better eye ( $P=.049)$. Twelve patients (5.1\%) reported that they "often" (5-7 times per year), "usually" (8-11 times per year) or "always" ran out of eye drops prior to a scheduled refill. Patients affected by this higher level ( $\geq 5$ times yearly) of eye drop bottle exhaustion were more likely to have poor visual acuity in their worse eye $\leq 20 / 70(P=.015)$ and had significantly lower worse-eye $\log$ MAR $(P=.043)$.

Conclusions: Self-reported early glaucoma bottle exhaustion regularly affected $5 \%$ of patients in our population and $25 \%$ reported early exhaustion at least once; the main risk factor was poor vision in at least one eye. These results may not be generalizable to a broad patient population, or to those inexperienced with eye drop self-administration. However, this pilot study compels further evaluation and consideration of early eye drop bottle exhaustion in glaucoma patients.
\end{abstract}

Keywords: Glaucoma, Eyedrop, Medication, Treatment, Adherence, Compliance, Visual impairment, Low vision, Blindness

\section{Background}

Glaucoma, the second leading cause of global blindness [1], is a progressive optic neuropathy with characteristic structural and functional abnormalities. Several clinical trials have demonstrated that reducing intraocular pressure (IOP) slows glaucoma progression [2,3], and proper use of topical ocular antihypertensives improves outcomes. However, numerous reports suggest

\footnotetext{
*Correspondence: pchen@uw.edu

'Department of Ophthalmology, University of Washington, 325 Ninth Ave, Seattle, WA 98104-2499, USA

Full list of author information is available at the end of the article
}

patients comply with only $70 \%$ or less of prescribed topical treatments [4-7].

Multiple reasons for poor adherence with topical glaucoma treatment have been implicated including situational and environmental factors, medication regimen, patient-related and provider-related factors [8]. Another barrier to patient compliance is an inadequate amount of medication available between scheduled prescription refills, because of difficulty in eye drop administration with resultant wastage. This is an issue in the United States (and may be in other developed nations) where prescription drug benefits ensure access to medication 
for most of the population, but also control the time interval before a refill may be obtained. This may also be of concern in less developed countries where access to and availability of medication may be limited. Although it is not uncommon in the clinic setting to hear patient complaints about the difficulty of getting refills if eye drop bottles are prematurely exhausted, no data exists in the literature regarding the prevalence of this phenomenon. Therefore we examined the prevalence of early exhaustion of glaucoma eye drops prior to a scheduled refill, and associated risk factors. Recent Centers for Medicare and Medicaid Services (CMS) changes now allow refills at $70 \%$ of the predicted days of use for patients with CMS-sponsored prescription drug coverage in the United States [9], which applies only to roughly $50 \%$ of the glaucoma patient population. As of late 2013, nine states also have passed and several others have pending legislation to provide coverage for all patients. The present study was based on patient recall over the year prior to institution of the CMS changes in a state without such legislation.

\section{Methods}

The Human Subjects Division of the University of Washington gave approval for this research survey. Patients were seen in glaucoma subspecialty clinics of the University of Washington from July 15, 2010 to December 31, 2010. Patients with a diagnosis of glaucoma who were prescribed long-term topical glaucoma therapy in both eyes and who self-administered drops were eligible for this study. The diagnosis of glaucoma was determined by standard ophthalmic examination and ancillary testing by fellowship-trained glaucoma specialists (PPC, RCM), and was based upon characteristic optic nerve appearance regardless of intraocular pressure or visual field findings. We chose to include only patients on bilateral treatment because we reasoned that patients using drops in only one eye on a traditional dosing regimen would be less likely to run out of medications. Because the personnel who administered the survey (CW, KLM) were not able to attend every glaucoma clinic at the University of Washington, not all eligible patients were enrolled. However, when the studyadministering personnel were present, all eligible subjects were asked if they wished to participate in a study of eye drop use (no mention was made of eye drop bottle exhaustion). Of the subjects approached to participate in the study, approximately ten refused to participate.

Patients were required to be on a stable, selfadministered drop regimen with no changes in their glaucoma therapy during the prior 3 months. After obtaining written informed consent, a short survey was completed (see Appendix) at the time of their office visit with the assistance of an in-person interviewer (CW, KLM).
The survey was developed by the authors and was based on clinical experience with patient complaints during glaucoma clinic visits; it was not further validated. Data was collected regarding insurance status, self reported incidence of early eye drop bottle exhaustion, specific drops used, specific drops that were exhausted early, and factors that the patient considered to be responsible for this occurrence. We reviewed the patients' medical records for additional data, including visual acuity and most recent visual field data, including mean deviation (MD), pattern standard deviation (PSD) and visual field index (VFI). No automated visual field data existed for some eyes with poor visual acuity. For bilateral data, we divided eyes into worse and better eyes, based on visual acuity (visual field data were used if visual acuities were equal in each eye). We considered an eye with Snellen visual acuity of 20/70 or worse to have poor visual acuity, corresponding to the World Health Organization definition of visual impairment [10]. We noted the presence of ophthalmic and medical comorbidities (arthritis was considered separately), and number of other prescription medications. Combination drops (e.g. dorzolamide-timolol) were considered to be one bottle, but two medications. In cases where glaucoma medications included oral medications prescribed for intraocular pressure reduction, these were not considered eyedrops. We did not collect data regarding the brand, fill or bottle type of the medications solicited. Statistical analysis was performed with SPSS 16.0 for Mac (SPSS, Chicago, IL).

\section{Results}

A total of 236 patients completed the survey during the study period. Baseline demographics and characteristics of the study population are presented in Table 1. Sixty patients (25.4\%) reported early exhaustion of eye drops at least once in the past year (Table 2). The sole risk factor significantly associated with this level of early bottle exhaustion was poor visual acuity $(\leq 20 / 70)$ in the better eye ( $5 / 9$ vs $55 / 227 ; \mathrm{P}=.049$, Fisher exact test) from any cause.

Twelve patients (5.1\%) reported that they "often" (5-7 times per year), "usually" (8-11 times per year) or "always" ran out of eye drops before they were able to refill their prescriptions. Risk factors for falling into this group included poor visual acuity $(\leq 20 / 70)$ in the worse eye from any cause $(P=.015)$, and worse $\log$ MAR visual acuity in the worse eye $(\mathrm{P}=.043)$ (Table 3$)$. Reasons for poor visual acuity $(\leq 20 / 70)$ for either eye are listed in Table 4. No other significant risk factors were found, specifically including systemic medical problems such as arthritis $(\mathrm{N}=47)$, diabetes mellitus $(\mathrm{N}=32)$, history of cerebrovascular accident $(\mathrm{N}=6)$, Parkinson's disease $(\mathrm{N}=5)$, essential tremor $(\mathrm{N}=7)$, and any peripheral neuropathy $(\mathrm{N}=6)(\mathrm{P}>.455$; data not shown $)$. No association 


\begin{tabular}{|c|c|}
\hline Age (years) & $67.7 \pm 14.0$ \\
\hline \multicolumn{2}{|l|}{ Sex } \\
\hline Female & 119 (50\%) \\
\hline Male & 117 (50\%) \\
\hline \multicolumn{2}{|l|}{ Visual field indices } \\
\hline \multirow[t]{3}{*}{ Better eye } & MD: $-4.2 \pm 5.7 \mathrm{~dB}$ \\
\hline & PSD: $4.2 \pm 3.4 \mathrm{~dB}$ \\
\hline & VFI: $90 \pm 16 \%$ \\
\hline \multirow[t]{3}{*}{ Worse eye } & MD: $-8.5 \pm 8.1 \mathrm{~dB}$ \\
\hline & PSD: $6.5 \pm 4.2 \mathrm{~dB}$ \\
\hline & VFI: $77 \pm 25 \%$ \\
\hline Duration of treatment & $7.9 \pm 5.9$ yrs \\
\hline No prescription insurance & $23(9.7 \%)$ \\
\hline Number of eye drop bottles & $2.1 \pm 0.8$ \\
\hline Number of comorbid conditions* & $2.3 \pm 1.8$ \\
\hline Number of prescription medications* & $3.3 \pm 3.2$ \\
\hline
\end{tabular}

Mean \pm SD; MD = mean deviation; $P S D=$ pattern standard deviation; $\mathrm{VFI}=$ visual field index.

*Other than glaucoma.

was found between lack of insurance $(\mathrm{N}=12,5 \%)$, or any type of insurance (Medicaid vs. Medicare vs. private), and early bottle exhaustion (data not shown).

Our survey included questions regarding possible reasons that the patient felt contributed to early bottle exhaustion, and 88 total responses were given (some patients listed more than one reason) (Table 5). Of these, the most frequently cited were "insufficient amount in bottle," "more than one drop comes out," "can't hold bottle steady," "can't see tip of bottle" and "size of the drops is too large." Some noted problems with the bottle, specifically that they are not clear, making it difficult to see when the amount of medication is running low. Only $4.5 \%$ reported the problem was due to missing the eye with the eye drop.

Among medications being used by at least $10 \%$ of subjects, the lowest rate of early bottle exhaustion was seen

Table 2 Frequency of reported inadequate eyedrop bottle volume

\begin{tabular}{lc}
\hline Frequency & $\mathbf{N}(\%)$ \\
\hline Rarely $(1-2 x / y r)$ & $29(12.3)$ \\
Sometimes $(3-4 x / y r)$ & $19(8.1)$ \\
Often $(5-7 x / y r)$ & $1(0.4)$ \\
Usually $(8-11 x / y r)$ & $4(1.7)$ \\
Always & $7(3.0)$ \\
Total & $60(25.4)$ \\
\hline
\end{tabular}

among subjects using brimonidine (4/74, 5.4\%), and the highest rate was seen with latanoprost $(13 / 80,16.3 \%)$ (Table 6).

\section{Discussion}

Poor adherence with treatment has been reported as a risk factor for progression to blindness in glaucoma patients [11-13]. This study evaluated the self-reported prevalence of early glaucoma eye drop bottle exhaustion and found $25 \%$ of patients reported their bottles did not last until the next allowed refill at least once yearly, and for $5 \%$ of patients this occurred on a regular basis (at least 5 times per year). The actual number of patients affected may be even greater, as self-reported non-anonymous studies may underestimate the prevalence of a given problem, due to response bias [14]. Recent CMS changes (at the United States national level) and some state Medicaid changes now allow refills of prescription drugs at $70 \%$ of the predicted days of use for patients with prescription drug coverage [9], but this only applies to patients who are Medicare beneficiaries who have enrolled in Part D; in 2011, approximately 13.5 million persons ( $28 \%$ of those enrolled in Medicare) were not covered by Part D plans [15]. In addition, nonMedicare prescription drug insurance plans are not required to follow the same CMS rules. As such, although there are many potential reasons patients who exhaust their medications earlier than a scheduled refill may not collect new medications, insurance restrictions have been a significant barrier in the United States.

We found an association between poor visual acuity in the worse eye (from any etiology, though in our study about one quarter of worse-affected eyes were damaged by glaucoma) and higher levels of early bottle exhaustion. One possible explanation for this finding may be "increased" adherence with therapy (perhaps better termed over-adherence) as compared to patients with less severe disease. Some investigators have suggested that fear of blindness is a motivator for adherence [16]. Similarly, patients considered glaucoma suspects are less adherent with therapy than patients diagnosed with glaucoma $[17,18]$. However if such over-adherence leads to early bottle exhaustion, this may only worsen advanced disease. Thus the individuals most affected by early bottle exhaustion are those who need their glaucoma medication the most those who have limited sight.

In addition, administration of eye drops requires dexterity and hand-eye coordination; good visual acuity and the ability to aim are necessarily interrelated [19]. Indeed, videotaping of glaucoma patients has shown they used an average of $1.4-1.8$ drops when trying to instill a single eye drop [20,21], which would result in a need to refill medications earlier than expected. A previous study evaluating disease severity and eye-drop administration 
Table 3 Selected risk factors for early eye drop bottle exhaustion among patients who report often, usually, or always running out of drops early (at least 5 times yearly)

\begin{tabular}{|c|c|c|c|}
\hline Factor & Yes, runs out & No, does not & $\mathbf{P}$ \\
\hline Age (yrs) & $71.7 \pm 11.3$ & $67.1 \pm 14.2$ & $.271^{*}$ \\
\hline Years of glaucoma drop use & $10.9 \pm 7.6$ & $7.8 \pm 5.8$ & $.070^{*}$ \\
\hline \multicolumn{4}{|l|}{ Poor visual acuity $(\leq 20 / 70)$} \\
\hline Better eye & $2 / 12(16.7 \%)$ & $7 / 224(3.1 \%)$ & $.070 \dagger$ \\
\hline Worse eye & $6 / 46(13.0 \%)$ & $6 / 190(3.2 \%)$ & $.015+$ \\
\hline \multicolumn{4}{|l|}{ logMAR visual acuity } \\
\hline Better eye & $.505 \pm 1.03$ & $.087 \pm .199$ & $.188^{*}$ \\
\hline Worse eye & $.881 \pm 1.06$ & $.397 \pm .787$ & $.043^{*}$ \\
\hline \multicolumn{4}{|l|}{ Visual field } \\
\hline Mean deviation $(\mathrm{dB})$, better eye & $-6.7 \pm 7.6$ & $-4.1 \pm 5.6$ & $.131^{*}$ \\
\hline Visual Field Index, better eye & $81 \pm 21$ & $90 \pm 16$ & $.198^{*}$ \\
\hline Mean deviation, worse eye & $-12.0 \pm 13.3$ & $-8.4 \pm 7.8$ & $.387^{*}$ \\
\hline Visual Field Index, worse eye & $63 \pm 40$ & $78 \pm 23$ & $.228^{*}$ \\
\hline Number of comorbid conditions (mean \pm SD) & $2.8 \pm 2.0$ & $2.3 \pm 1.8$ & $.274^{*}$ \\
\hline Number of prescription medications (not including eye drops) & $5.3 \pm 5.4$ & $3.2 \pm 3.0$ & $.228^{*}$ \\
\hline Number of bottles & $2.1 \pm 1.2$ & $2.1 \pm 0.8$ & $.962 \dagger$ \\
\hline Number of eye drops/day & $6.2 \pm 4.5$ & $6.6 \pm 3.8$ & $.235+$ \\
\hline
\end{tabular}

${ }^{*} t$-test, 2-tail; + Chi square or Fisher Exact test, 2-tail.

found that in patients with asymmetric glaucoma, there was a significant association between worse instillation technique and the eye with greater visual field loss [22]. Visual field data was not associated with early bottle exhaustion in our patient population, though this is probably related to the lack of automated visual field testing in eyes with very poor visual acuity. Systemic conditions such as cerebrovascular accident, tremor, Parkinson's disease, and peripheral neuropathy were poorly represented in

Table 4 Reasons for reduced visual acuity $(\leq 20 / 70)$

\begin{tabular}{lcc}
\hline Primary reason for reduced visual acuity & $\begin{array}{c}\text { Better eye } \\
(\mathbf{N}=\mathbf{9})\end{array}$ & $\begin{array}{c}\text { Worse eye } \\
(\mathbf{N}=45)\end{array}$ \\
\hline Glaucoma (any type) & $1(11 \%)$ & $11(24 \%)$ \\
Retinal vein occlusion & 0 & $6(13 \%)$ \\
Age-related macular degeneration & $2(22 \%)$ & $5(11 \%)$ \\
Myopic retinal degeneration & $2(22 \%)$ & $5(11 \%)$ \\
Cataract & 0 & $3(7 \%)$ \\
Amblyopia & $1(11 \%)$ & $3(7 \%)$ \\
Retinal detachment & 0 & $3(7 \%)$ \\
Dry eye disease & $1(11 \%)$ & $2(4 \%)$ \\
Posterior uveitis & $1(11 \%)$ & $2(4 \%)$ \\
Diabetic retinopathy & 0 & $1(2 \%)$ \\
Other* & $1(11 \%)$ & $4(9 \%)$ \\
\hline
\end{tabular}

*Includes Non-arteritic ischemic optic neuropathy, retinopathy of prematurity, irregular astigmatism after penetrating keratoplasty, macular hole. our study population, possibly because we excluded patients who did not administer their own drops, and patients severely afflicted by the aforementioned diseases probably must rely on caretakers to administer their eyedrop medications.

Although many of the factors cited by our subjects as reasons for early bottle exhaustion are likely amenable only to personalized instruction or use of an eyedrop dispensing aid, some of them might be amenable to changes in eye drop bottle manufacture: such as colored bottle tips that would allow patients to see the tip of the bottle more easily, clear or translucent bottles so patients could see when they are running low on medication, and

Table 5 Patient questionnaire responses regarding factors contributing to early bottle exhaustion

\begin{tabular}{lc}
\hline Patient-reported reason for early bottle exhaustion & N (\%) \\
\hline More than one drop comes out & $27(30.6)$ \\
Insufficient amount in bottle & $16(18.1)$ \\
Drop size too large/inconsistent & $16(18.1)$ \\
Can't see tip of bottle & $10(11.4)$ \\
Can't hold bottle steady & $8(9.1)$ \\
Misses eye & $4(4.5)$ \\
Not sure why & $3(3.4)$ \\
Poor vision & $2(2.3)$ \\
Can't see if bottle empty & $2(2.3)$ \\
\hline
\end{tabular}




\begin{tabular}{|c|c|c|c|}
\hline Medication & $\begin{array}{l}\mathrm{N} \text { patients } \\
\text { using drop }\end{array}$ & $\begin{array}{c}\mathrm{N} \text { (\%) any early } \\
\text { exhaustion }\end{array}$ & $\begin{array}{l}N(\%) \text { frequent } \\
\text { early exhaustion }\end{array}$ \\
\hline Timolol/Dorzolamide & 89 & $7(7.9)$ & $4(4.5)$ \\
\hline Latanoprost & 80 & $13(16.3)$ & $3(3.8)$ \\
\hline Brimonidine & 74 & $4(5.4)$ & $1(1.3)$ \\
\hline Timolol & 64 & $10(14.5)$ & $3(4.7)$ \\
\hline Travoprost & 66 & $10(15.2)$ & $3(4.5)$ \\
\hline Bimatoprost & 41 & $6(14.6)$ & $2(4.9)$ \\
\hline Dorzolamide & 18 & 0 & 0 \\
\hline Pilocarpine & 17 & $2(11.7)$ & 0 \\
\hline Brinzolamide & 16 & $2(12.5)$ & 0 \\
\hline Timolol/Brimonidine & 5 & $1(20.0)$ & 0 \\
\hline Apraclonidine & 5 & $1(20.0)$ & 0 \\
\hline Betaxolol & 5 & $2(40.0)$ & 0 \\
\hline Carteolol & 5 & $2(40.0)$ & 0 \\
\hline Levobunolol & 3 & 0 & 0 \\
\hline
\end{tabular}

development and distribution of aids for eye drop instillation (or greater adoption of existing instillation aids) among those at risk for early bottle exhaustion. Although the reasons we listed on the survey might appear to direct our subjects' responses, in fact $43 \%$ of responses were listed under "other." Clearly, given the difficulty in eye drop administration, the development of an alternative eye drop delivery system would be welcome.

No association was found between medical insurance status nor prescription drug insurance status, and early eye drop bottle exhaustion, although only a small proportion of our study population was uninsured. While we did not collect data on out-of-pocket drug cost or socioeconomic data for our subjects, the lack of association seen with insurance status or type implies that socioeconomic status may not influence the rate of early bottle exhaustion, which is consistent with other studies that have looked at other sociodemographics such as educational level $[6,13,23,24]$. A reasonable conclusion, based on our findings and those of other authors, would be that problems with eye drop administration are present across socioeconomic stations and are not related to drug cost or insurance status.

That patients with glaucoma may have poor adherence to topical treatment is not a novel finding. The usual implication is that insufficient medicine is taken despite adequate supply [23-25], although some authors have found that $7-13 \%$ of patients overused topical glaucoma drops on a regular basis, 6-7 days per month [5,26]. Our study suggests that providers must also be cognizant of early bottle exhaustion when managing glaucoma patients. Patients with poor vision may have particular difficulty with this issue; unfortunately, these may be the patients that need well-controlled IOP the most. However, treatment should be individualized, since a multitude of factors may interfere with compliance [8]. Medication insurers and pharmacy staff should acknowledge that some patients will have early bottle exhaustion, and should make allowances for early eye drop bottle refills, as is currently permitted under Medicare Part D. Although patients desire personalized instruction on eyedrop administration [27], and while it makes sense that improved training of patients in eyedrop self-administration might also reduce the number of patients that have difficulty with this basic aspect of glaucoma treatment, there is currently no evidence in the literature that supports such a contention [28].

Several limitations of our study must be acknowledged. Our data collection relied solely on patient recall, and was not validated with pharmacy refill data, with observation of eye drop instillation practices or with patient involvement. We studied a relatively small population at a single academic center, and our results may not be generalizable to other populations. Given the small number of patients with higher levels of early bottle exhaustion, our findings on risk factors for early bottle exhaustion should be interpreted with caution. Response bias may have led some patients to minimize or maximize the extent of their difficulties, although we attempted to word our survey carefully in an attempt to avoid such bias. Further investigation of this subject might focus on a larger sample size, prospective measurement via pharmacy refill data, use of eye drop application aids among patients who report difficulty with early eye drop bottle exhaustion and length of time patients must go without medication, as well as coping mechanisms that patients employ to "stretch out" their medication eye drop supply.

\section{Conclusions}

Self-reported early glaucoma bottle exhaustion regularly affected $5 \%$ of patients in our glaucoma clinic population, and $25 \%$ reported early exhaustion at least once yearly; the main risk factor was poor vision (Snellen acuity of 20/70 or worse) in at least one eye. Our survey was only conducted on experienced eyedrop users who self-adminstered their eyedrops bilaterally, and therefore these results may not be generalizable to a broad patient population with patients suffering from numerous medical issues, or with those inexperienced with eye drop self-administration. However, this pilot study compels further data collection and research, and consideration of early eye drop bottle exhaustion in at-risk glaucoma patients in the clinic. 


\section{Appendix: Eye drop use survey}

1. How many different bottles of glaucoma eye drops do you use?

$1 \_2 \_3$ _ 4 or more

2. Do you have any kind of insurance plan that helps to pay for your glaucoma eye drops?

a. Yes

If yes, is this Medicare Part D? Yes

No

If yes, name of insurance (if known)

b. No

3. How often do you think you run out of eye drops before the end of the month, or before your insurance company will allow you to re-order your drops?

a. Never

b. Rarely - not more than once or twice per year

c. Sometimes -3 to 4 times per year

d. Often -5 to 7 times per year

e. Usually - 8 to 11 times per year

f. Always

4. Which of your medications usually runs out early?

Name of medication(s)

It varies, cannot say

5. Why do you think you usually run out of drops earlier than you are supposed to? Check all that apply.

I miss my eye because I can't see the bottle tip well

I miss my eye because I can't hold the bottle steady

More than one drop comes out

The size of the drops is too large

Other reason (please list)

\section{Competing interests}

Supported in part by a Departmental Grant from Research to Prevent Blindness, Inc., New York, NY and the University of Washington Glaucoma Research Fund. No sponsor had any role in the design or conduct of this research. None of the authors has financial interest or any form of conflicting interest in any aspect of this manuscript.

\section{Authors' contributions}

DBM participated in data analysis and preparation of the manuscript. CW participated in patient recruitment and data collection. KLM participated in patient recruitment and data collection. MAS participated in data analysis and preparation of the manuscript. RCM participated in patient recruitment and data collection. PPC participated in study design, patient recruitment, data collection, data analysis and preparation of the manuscript. All authors read and approved the final manuscript.

\section{Author details}

'Department of Ophthalmology, University of Washington, 325 Ninth Ave, Seattle, WA 98104-2499, USA. ${ }^{2}$ Seattle University, Seattle, WA, USA.

Received: 20 September 2013 Accepted: 4 June 2014

Published: 13 June 2014

\section{References}

1. Quigley HA, Broman AT: The number of people with glaucoma worldwide in 2010 and 2020. Br J Ophthalmol 2006, 90:262-267.

2. Leske MC, Heij A, Hussein M, Bengtsson B, Hyman L, Komaroff E, Early Manifest Glaucoma Trial Group: Factors for glaucoma progression and the effect of treatment: the Early Manifest Glaucoma Trial. Arch Ophthalmol 2003, 121:48-56

3. The AGIS Investigators: The Advanced Glaucoma Interventional Study (AGIS): 7, the relationship between control of intraocular pressure and visual field deterioration. Am J Ophthalmol 2000, 130:429-440.

4. Gordon ME, Kass MA: Validity of standard compliance measures in glaucoma compared with an electronic eye drop monitor. In Patient Compliance in Medical Practice and Clinical Trials. Edited by Cramer JA, Spiker B. New York: Raven; 1991:163-173.

5. Kass MA, Meltzer DW, Gordon M, Cooper D, Goldberg J: Compliance with topical pilocarpine treatment. Am J Ophthalmol 1986, 101:515-523.

6. Okeke CO, Quigley HA, Jampel HD, Ying GS, Plyler RJ, Jian Y, Friedman DS Interventions improve poor adherence with once daily glaucoma medications in electronically monitored patients. Ophthalmology 2009 116:2286-2293.

7. Hermann MM, Bron AM, Creuzot-Garcher CP, Diestelhorst M: Measurement of adherence to brimonidine therapy for glaucoma using electronic monitoring. J Glaucoma 2011, 20:502-508.

8. Tsai JC, McClure CA, Ramos SE, Schlundt DG, Pichert JW: Compliance barriers in glaucoma: a systematic classification. J Glaucoma 2003, 12:393-398.

9. Department of Health and Human Services. Centers for Medicare and Medicaid Services: Early refill edits on topical ophthalmic products. 2010. http://www.cms.gov/Medicare/Prescription-Drug-Coverage/ PrescriptionDrugCovContra/Downloads/MemoEarlyRefillOpth_060210.pdf Accessed June 6, 2014

10. Murdoch IE, Jones BR, Cousens S, Liman I, Babalola OE, Dauda J, Abiose A Visual field constriction as a cause of blindness or visual impairment. Bull World Health Organ 1997, 75(2):141-146.

11. Chen PP: Blindness in patients with treated open-angle glaucoma. Ophthalmology 2003, 110:726-733.

12. Kooner KS, Albdoor M, Cho BJ, Adams-Huet B: Risk factors for progression to blindness in high tension primary open angle glaucoma: comparison of blind and nonblind subjects. Clin Ophthalmo/ 2008, 2:757-762.

13. Sleath B, Blalock S, Covert D, Stone JL, Skinner AC, Muir K, Robin AL: The relationship between glaucoma medication adherence, eye drop technique, and visual field defect severity. Ophthalmology 2011, 118:2387-2402.

14. O'Leary TE, Diller $L$, Recklitis $C J$ : The effects of response bias on selfreported quality of life among childhood cancer survivors. Qual Life Res 2007, 16:1211-1220.

15. Medicare Payment Advisory Commission: Status Report on Part D, With Focus on Beneficiaries With High Drug Spending. In Report to the Congress: Medicare Payment Policy. Washington DC: MedPAC; 2012:339-370.

16. Lacey J, Cate H, Broadway C: Barriers to adherence with glaucoma medications: a qualitative research study. Eye 2009, 23:924-932.

17. Kosoko O, Quigley HA, Vitale S, Enger C, Kerrigan L, Tielsch JM: Risk factors for noncompliance with glaucoma follow-up visits in a residents' eye clinic. Ophthalmology 1998, 105:2105-2111.

18. Nordstrom BL, Friedman DS, Mozaffari E, Quigley HA, Walker AM: Persistence and adherence with topical glaucoma therapy. Am J Ophthalmol 2005, 140:598-606.

19. Winfield AJ, Jessiman D, Williams A, Esakowitz L: A study of the causes of non-compliance by patients prescribed eyedrops. Br J Ophthalmol 1990, 74:477-480.

20. Stone $J$, Robin AL, Novack GD, Covert DW, Cagle GD: An objective evaluation of eyedrop instillation in patients with glaucoma. Arch Ophthalmol 2009, 127:732-736.

21. Hennessy AL, Katz J, Covert D, Protzko C, Robin AL: Videotaped evaluation of eyedrop instillation in glaucoma patients with visual impairment or moderate to severe visual field loss. Ophthalmology 2010, 117:2345-2352.

22. Aptel $H$, Masset $H$, Burillon C, Robin A, Denis P: The influence of disease severity on quality of eye-drop administration in patients with glaucoma or ocular hypertension. Br J Ophthalmol 2009, 93:700-701.

23. Friedman DS, Okeke CO, Jampel HD, Ying GS, Plyler RJ, Jiang Y, Quigley HA: Risk factors for poor adherence to eyedrops in electronically monitored patients with glaucoma. Ophthalmology 2009, 116:1097-1105.

24. Rees G, Leong O, Crowston JG, Lamoureux EL: Intentional and unintentional nonadherence to ocular hypotensive treatment in patients with glaucoma. Ophthalmology 2010, 117:903-908. 
25. Gurwitz JH, Glynn RJ, Monane M, Everitt DE, Gilden D, Smith N, Avorn J: Treatment for glaucoma: adherence by the elderly. Am J Pub Health 1993, 83:711-716

26. Kass MA, Gordon M, Morley RE Jr, Meltzer DW, Goldberg JJ: Compliance with topical timolol treatment. Am J Ophthalmol 1987, 103(2):188-193.

27. Taylor SA, Galbraith SM, Mills RP: Causes of non-compliance with drug regimens in glaucoma patients: a qualitative study. J Ocul Pharmacol Ther 2002, 18(5):401-409.

28. Waterman H, Evans JR, Gray TA, Henson D, Harper R: Interventions for improving adherence to ocular hypotensive therapy. Cochrane Database Syst Rev 2013, 4:CD006132. doi:10.1002/14651858.CD006132.pub3.

doi:10.1186/1471-2415-14-79

Cite this article as: Moore et al:: Prevalence of self-reported early glaucoma eye drop bottle exhaustion and associated risk factors: a patient survey. BMC Ophthalmology 2014 14:79.

\section{Submit your next manuscript to BioMed Central and take full advantage of:}

- Convenient online submission

- Thorough peer review

- No space constraints or color figure charges

- Immediate publication on acceptance

- Inclusion in PubMed, CAS, Scopus and Google Scholar

- Research which is freely available for redistribution 